\section{Biliorenous fistula related to self-expandable biliary metallic stent placement: a rare complication of endoscopic retrograde cholangiopancreatography}

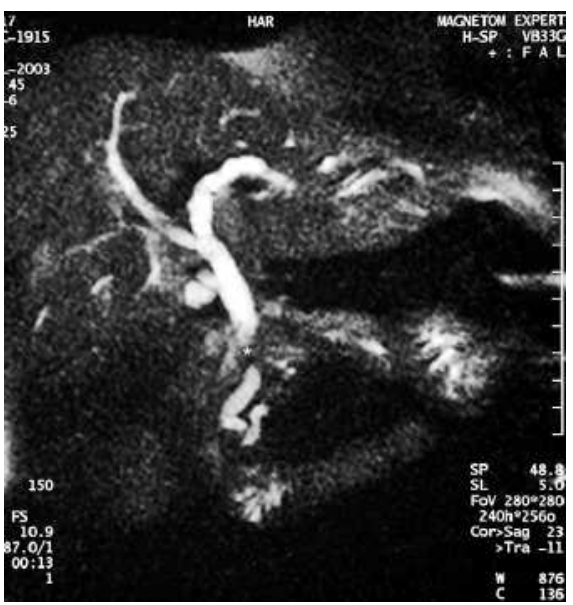

Figure 1 Magnetic resonance cholangiopancreatographic image showing the bile duct stenosis caused by cholangiocarcinoma (asterisk).

An 87-year-old woman was admitted to our hospital with cholangitis caused by a cholangiocarcinoma (Figure $\mathbf{1}$ ). She refused surgery, so a self-expandable metallic stent (SEMS) (Memotherm; Bard Inc. Billerica, Massachusetts, USA) was placed endoscopically. One year later, she presented with cholangitis related to tumor progression. We placed a second and a third coaxial "Y"-shaped SEMS (Luminexx, Bard Inc. Billerica, Massachusetts, USA) in the right and left bile ducts. Over the following 4 months she was admitted three times with sepsis of biliary origin, which resolved after cleansing of biliary sludge from the lumen of the stents. In the last episode, when contrast was injected at the proximal end of the right bile duct stent, a leak of contrast with rapid and turbulent flow was clearly seen, indicative of a biliovascular fistula (Figure 2). We cleared out the bile duct once again and her symptoms resolved. She died 4 months later after general deterioration in her condition.

Bilhemia occurs when the hepatic vessels and the bile ducts are in communication and the pressure is higher in the latter, leading to flow of bile into the bloodstream [1,2]. In our case, taking into account the location of the fistula and the
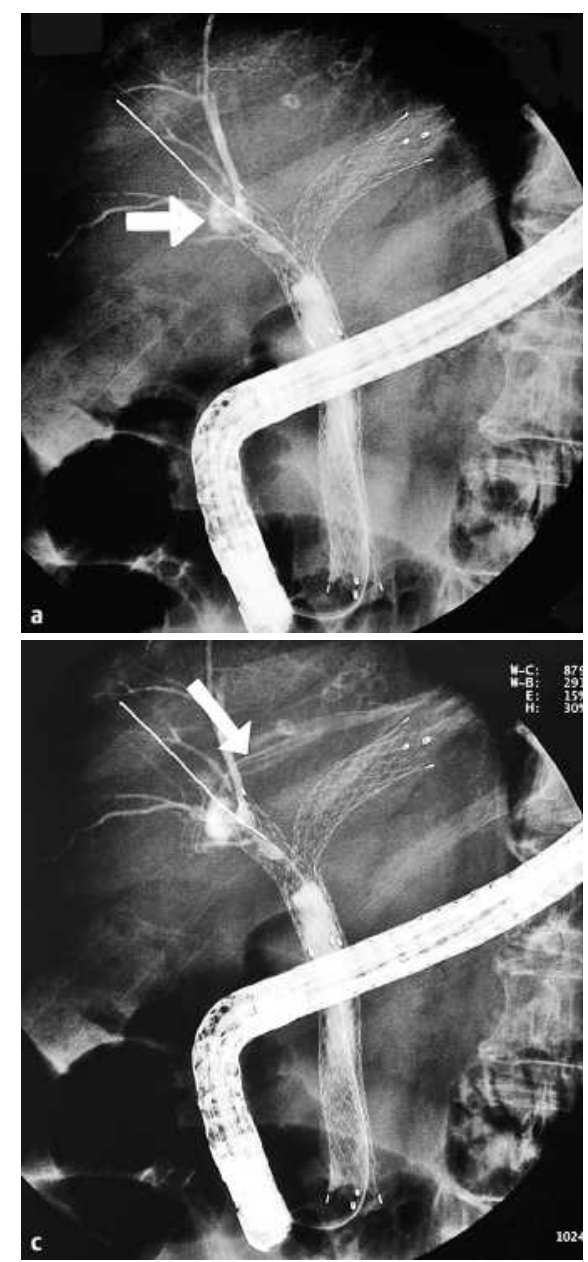

Figure 2 The intrahepatic portions of the stents were occluded by tumor growth and biliary sludge, and a necrotic area in the proximal end of the right bile duct stent can be seen, marked by the arrow (a). When contrast was injected, a leak of contrast emerg-

temporal relationship between the onset of bacteremia and stent placement, we believe that the fistula was created after the opening of the proximal end of the right-sided stent, which led to focal necrosis and created a communication with the vascular tree at this level. When the bile duct pressure became progressively higher as a result of tumor growth and sludge formation, small amounts of infected bile entered the bloodstream, causing bacteremia. The endoscopic management of bilhemia is based on reducing the pressure in the bile duct by placement of a
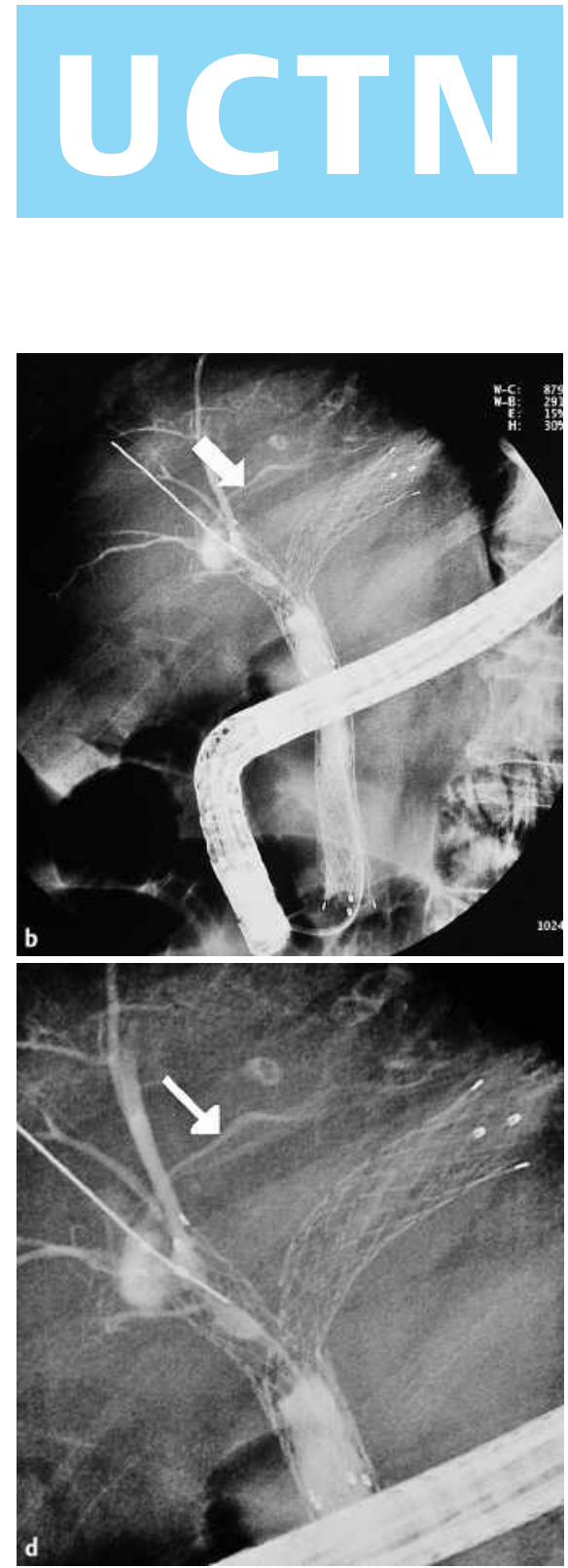

ing from the necrotic area was seen (arrow), with turbulent flow and rapid drainage, corresponding to the biliovascular fistula $(\mathbf{b}, \mathbf{c})$. The final image shows a more detailed view of the fistula (arrow) (d).

biliary stent or by nasobiliary drainage. However, the patients who have been treated endoscopically for this complication previously were young and had benign disease $[1,3,4]$. The therapeutic decisions we made in this case were guided by our patient's age, poor general condition, and prognosis.

DOI: 10.1055/s-2006-945169 


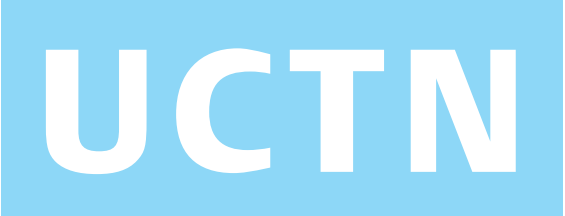

Endoscopy_UCTN_Code_CPL_1AK_2AD

J. J. Vila, F. J. Jiménez, R. Irisarri,
M. Vicuña, B. Martínez, F. Borda Gastroenterology Department, Hospital de Navarra, Pamplona, Spain.
References

${ }^{1}$ Auroux J, Dumonceau JM, Cremer M, Deviere $\mathrm{J}$. Endoscopic treatment of bilhemia complicating percutaneous transhepatic biliary drainage. Endoscopy 2000; 93: 1952 - 1955

2 Sandblom P, Jakobsson B, Lindaren H, Lunderquist A. Fatal bilhemia. Surgery 2000; 127: $354-357$

${ }^{3}$ Gable DR, Allen JW, Harrell DJ, Carrillo EH. Endoscopic treatment of posttraumatic "bilhemia“: case report. J Trauma 1997; 46: $276-279$

${ }^{4}$ Sears RJ, Ishitani MB, Bickston SJ. Endoscopic diagnosis and therapy of a case of bilhemia after percutaneous liver biopsy. Gastrointest Endosc 1997; 46: 276-279
Corresponding author

\section{J. J. Vila, M.D.}

Gastroenterology Department Hospital de Navarra

c) Irunlarrea 3

31008 Pamplona

Navarra

Spain

Fax: $\quad+34-848-422303$

Email: xoanxose@hotmail.com 